\title{
BMJ Open Observational study on the current status of thalassaemia in Malaysia: a report from the Malaysian Thalassaemia Registry
}

\author{
Hishamshah Mohd Ibrahim (D) ,,2 Zulaiha Muda, ${ }^{2}$ Ida Shahnaz Othman, ${ }^{2}$ \\ Mohamed Najib Mohamed Unni, ${ }^{2}$ Kok Hoi Teh, ${ }^{2}$ Asohan Thevarajah, ${ }^{3}$ \\ Kogilavani Gunasagaran, ${ }^{3}$ Gek Bee Ong, ${ }^{4}$ Seoh Leng Yeoh, ${ }^{5}$ \\ Aisyah Muhammad Rivai, ${ }^{6}$ Che Hadibiah Che Mohd Razali, ${ }^{7}$ Nazzlin Dizana Din, ${ }^{8}$ \\ Zarina Abdul Latiff, ${ }^{9}$ Rahman Jamal, ${ }^{10}$ Norsarwany Mohamad, ${ }^{11}$ \\ Hany Mohd Ariffin, ${ }^{12}$ Hamidah Alias (D) ${ }^{9}$
}

To cite: Mohd Ibrahim H, Muda Z, Othman IS, et al. Observational study on the current status of thalassaemia in Malaysia: a report from the Malaysian Thalassaemia Registry. BMJ Open 2020;10:e037974. doi:10.1136/ bmjopen-2020-037974

- Prepublication history and additional material for this paper are available online. To view these files, please visit the journal online (http://dx.doi. org/10.1136/bmjopen-2020037974).

Received 23 February 2020 Revised 12 May 2020 Accepted 29 May 2020

Check for updates

(c) Author(s) (or their employer(s)) 2020. Re-use permitted under CC BY-NC. No commercial re-use. See rights and permissions. Published by BMJ.

For numbered affiliations see end of article.

Correspondence to

Dr Hamidah Alias;

midalias@ppukm.ukm.edu.my

\section{ABSTRACT}

Objective Thalassaemia is the most common inherited blood disorder in Malaysia. This study aims to report the current status of thalassaemia in Malaysia and provide a comprehensive understanding of the disease through data obtained from the Malaysian Thalassaemia Registry.

Design Data were extracted from the Malaysian Thalassaemia Registry, a web-based system accessible to enrolled users through www.mytalasemia.net.my. Setting The Malaysian Thalassaemia Registry data was recorded from reports obtained from 110 participating government and university hospitals in Malaysia.

Participants The patients were those attending the 110 participating hospitals for thalassaemia treatment. Intervention Data were collected from the Malaysian Thalassaemia Registry from 2007 until the fourth quarter of 2018.

Primary outcome measure 7984 out of 8681 patients with thalassaemia registered in the Malaysian Thalassaemia Registry were reported alive.

Results Majority of the patients were reported in the state of Sabah (22.72\%); the largest age group affected was 5.0-24.9 years old (64.45\%); the largest ethnic group involved was Malay (63.95\%); and the major diagnosis was haemoglobin $\mathrm{E} / \mathrm{\beta}$-thalassaemia $(34.37 \%)$. From the 7984 patients, $56.73 \%$ were on regular blood transfusions and $61.72 \%$ were on chelation therapy. A small fraction $(14.23 \%)$ has undergone splenectomy, while the percentage of patients with severe iron overload (serum ferritin $\geq 5000 \mu \mathrm{g} / \mathrm{L}$ ) reduced over time. However, cardiac complications are still the main cause of death in patients with thalassaemia.

Conclusion Data gathered into the registry can be used to understand the progression of the disorder, to monitor iron overload management and to improve the outcomes of treatment, to enhance preventive strategies, reduce healthcare burden and improve the quality of life. Sustainability of the Malaysian Thalassaemia Registry is important for surveillance of thalassaemia management in the country and help the national health authorities to develop more effective policies.

\section{Strengths and limitations of this study}

- The Malaysian Thalassaemia Registry is the first online patient registry in Malaysia which aggregates data from all participating hospitals and allows realtime data analysis.

- This is the largest nationwide report that describes the overall distribution, current disease status and the progress of management of patients with thalassaemia in Malaysia.

- Some missing data in a few variables during data collection and non-participating centres that treat a small number of patients with thalassaemia made this survey susceptible to reporting bias.

- Data presented describe the findings of study as at fourth quarter of the year 2018. Figures might differ at different time points due to the dynamic nature of the registry.

\section{INTRODUCTION}

Thalassaemia is one of the most common autosomal recessive disorders and is highly prevalent in countries within the tropical belt, including Malaysia. ${ }^{12}$ Current estimation shows that $6.8 \%$ of Malaysians are thalassaemia carriers who might be affected with various degrees of anaemia. ${ }^{3} \mathrm{~A}$ thalassaemia carrier couple has a $25 \%$ chance of producing a thalassaemia major progeny.

Caused by a wide spectrum of point mutations and gene deletions, thalassaemia leads to a reduced or zero formation of the $\alpha$ - or $\beta$-globin chain sub-units of the adult haemoglobin $(\mathrm{Hb})$ molecule. ${ }^{3}$ The deficiency produces fragile erythrocytes and haemolytic anaemia. The affected babies will eventually develop progressively severe anaemia and require life-long blood transfusions to meet 
their daily physiological needs. ${ }^{4}$ Iron chelation therapy must accompany the regular transfusions to reduce iron overload, allow normal growth and improve the survival rates of patients with thalassaemia. ${ }^{56}$

Although thalassaemia is the most common hereditary haematological disorder in Malaysia, information on nationwide geographical distribution of patients, socioeconomic and clinical data including treatment outcomes is still lacking. Due to concern over its public health burden on the country, the Malaysian Cabinet endorsed a national comprehensive thalassaemia programme on 25 August 2004, consisting of health education and population awareness drive, screening initiative, comprehensive clinical management and establishing a Malaysian Thalassaemia Registry (MTR). The registry was officially launched on 12 May 2007, an initiative to identify and collect detailed epidemiological and clinical data of patients with thalassaemia from all over the country who received treatment at government hospitals under the Ministry of Health $(\mathrm{MOH})$ and university hospitals under the Ministry of Education. The registry is the first online patient registry in Malaysia featuring real-time data entry, facilitates update and data reporting, and allows enrolled users to observe the aggregated data at any point of time. The core data set of essential data elements was predefined by a team of experts including clinicians and the completeness and validity of data collection was ensured by joined cooperation between the company in charge and $\mathrm{MOH}$, Malaysia. Site visits to ensure accuracy and completeness of the data were carried out by a team of research assistants appointed by the $\mathrm{MOH}$ and working in collaboration with the company. A regular internal audit for quality control of the MTR is performed by the company in charge. The web-based system is accessible to enrolled users through www.mytalasemia.net.my (МyTalasemia). It is user friendly and can be managed from different locations. The MTR demonstrates the value of a continuously updated registry for the surveillance of health services pertaining to thalassaemia in the country. Patient registries, which include usage of large set of data, have been reported to be helpful in mapping the functionalities and providing a positive return on investment. ${ }^{7}$

Herein, we report the data obtained from the MTR from 2007 to November 2018, unravelling the current trend of thalassaemia in Malaysia. This work provides a near comprehensive understanding of thalassaemia in Malaysia nationwide.

\section{METHODS}

The updated MTR included all patients diagnosed with thalassaemia from 2007 to November 2018 in 110 participating centres ( 107 government hospitals and 3 university hospitals), located in 13 states and three Federal Territories of Malaysia (Kuala Lumpur, Labuan and Putrajaya). The updated data from the registry was retrieved in November 2018 for analysis. This study utilised secondary data, involving data that have been gathered by the $\mathrm{MOH}$ for national census. The patients' data from diagnosis to last follow-up or death were retrospectively collected by research assistants in various regional centres in Malaysia. They were supervised and all data were verified by clinicians and then manually entered into the MyTalasemia system. All research assistants had centrally undergone training on data collection and recording onto the webbased system. The types of data collected were guided by the registry design. Data elements were grouped into several categories including socio-demography, clinical characteristics, laboratory test results, type of treatment received, death record and complications. Duplicate registration was prevented. The updated data were further verified and discussed centrally during the annual National Thalassaemia Meeting held in November.

In this report, the data was separated into two groups: (1) alive patients and (2) deceased patients. In the alive patient group the following variables were analysed: (1) demography (location, gender, age groups and ethnicity); (2) clinical diagnosis; (3) receipt of regular blood transfusions; (4) receipt of chelation therapy; (5) history of splenectomy; and (6) serum ferritin levels. In deceased patients, the causes of death were reported.

Results were presented as fractions and percentages over the total number of reported cases. For demographic characteristics of regions, age groups and ethnicity, the fractions and percentages were calculated against the total number of reported cases in the respective groups.

\section{Patient and public involvement}

This report was prepared without patients and public involvement. Patients and the public were not invited to comment on the database and study design or to contribute to the writing or editing of this report.

\section{RESULTS}

As of 28 November 2018, 8681 patients with thalassaemia have been registered in the MTR. Out of 8681 patients, $7984(91.97 \%)$ were reported to be alive and 130 of those alive $(1.63 \%)$ were reported cured by stem cell transplantation. Another 614 patients $(7.69 \%)$ were lost to follow-up. The remaining 697 patients $(8.03 \%)$ had deceased.

\section{Geography}

The largest number of registered patients with thalassaemia came from the state of Sabah $(1814 / 7984$ cases, $22.72 \%$ ), followed by the state Selangor (14.64\%), Kedah $(8.69 \%)$, Johor $(7.98 \%)$ and Perak $(7.06 \%)$. Figure 1 shows the map of Malaysia with the cumulative numbers of registered patients with thalassaemia in each state of Peninsular Malaysia, Sabah and Sarawak.

The patient geographical distribution was also analysed based on regional division: Peninsular Malaysia (which includes 11 states and the Federal Territory of Kuala Lumpur and Putrajaya), Sabah (Sabah and the Federal Territory of Labuan) and Sarawak. Peninsular Malaysia 


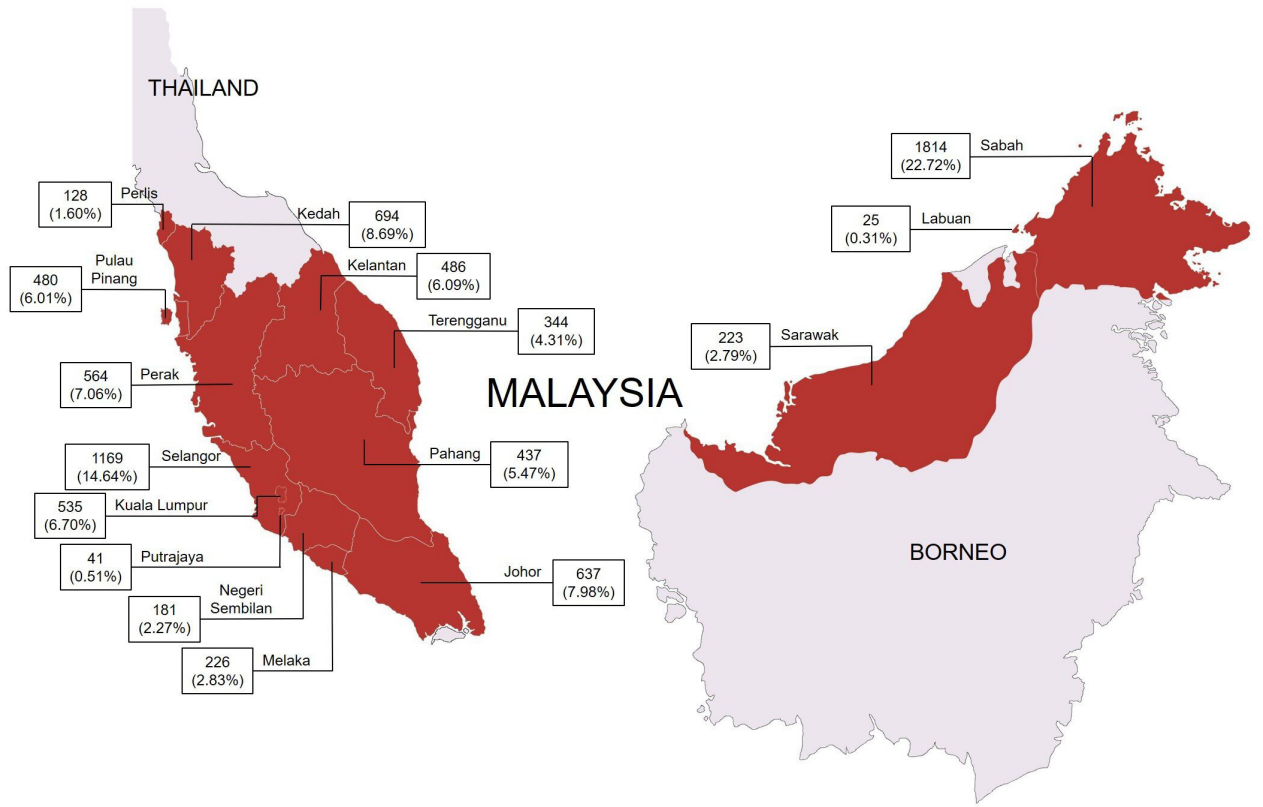

Figure 1 Cumulative numbers of registered patients with thalassaemia in each state of Malaysia.

recorded a $5922(74.17 \%)$ registered patients, while Sabah and Sarawak had registered 1839 (23.03\%) and $223(2.79 \%)$ patients, respectively.

Hospital Ampang in the state of Selangor recorded the highest number of patients $(703,8.81 \%)$ seen since the hospital serves as a referral centre for adult patients with thalassaemia, including patients from the capital of Malaysia, Kuala Lumpur. Hospital Queen Elizabeth and Hospital Wanita dan Kanak-Kanak Likas, both located in Sabah, also recorded a high number of patients (370, $(4.63 \%)$ and $300,(3.76 \%)$, respectively).

\section{Gender}

Gender distribution among the recorded patients with thalassaemia was almost equal, with a male to female ratio of 49.60:50.40 (3960 vs 4024).

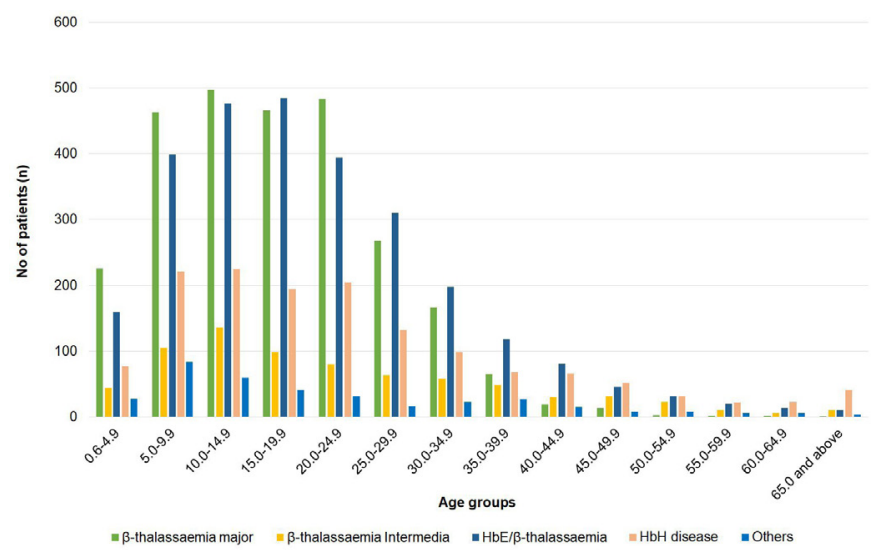

Figure 2 Distribution of cumulative number of registered cases in year 2018 in the Malaysian Thalassaemia Registry according to age groups. $\mathrm{HbE}$, haemoglobin $\mathrm{E} ; \mathrm{HbH}$, haemoglobin $\mathrm{H}$.

\section{Age groups}

Majority of the patients were in the group of 5.0-24.9 years of age (5146/7984 patients, $64.45 \%)$, and the largest number of patients were aged between 10.0 and 14.9 years $(1394,17.46 \%)$. The number of patients decreased in the older age groups, from 790 patients $(9.89 \%)$ in the 25.0 29.9 years age group to five patients $(0.06 \%)$ in the 85.0 89.9 years age group. Figure 2 depicts the distribution of cumulative number of registered cases in year 2018 in the MTR according to age groups. Table 1 shows the distribution of registered cases according to age groups and the three main geographical regions in Malaysia.

\section{Ethnicity}

The majority of the registered patients with thalassaemia were Malay $(5106 / 7984,63.95 \%$ ), followed by Chinese (938, 11.75\%) and Kadazan-Dusuns (907, 11.36\%). Other specified ethnicities include Pribumi Sabah (213, $2.67 \%)$, Bajau (196, 2.45\%), Murut (147, 1.84\%), Rungus $(112,1.40 \%)$ and Indian $(43,0.54 \%)$. The remaining ethnicities such as Orang Asli, Thais, Iban, Bidayuh, Sino Kadazan and Melanau $(322,4.03 \%)$ are listed as 'Others', along with 68 patients from foreign countries.

Comparison was also made according to regional division. The data showed that the Malay made up $82.81 \%$ of registered patients in Peninsular Malaysia (4904/5922 patients). Patients in Sarawak, on the other hand, were mostly Malay $(95 / 223,42.60 \%)$ and Chinese (86/223, $38.57 \%$ ), while patients in Sabah comprised mainly of Kadazan-Dusun $(864 / 1839,46.98 \%)$ and other Sabah's Indigenous $(673 / 1839,36.60 \%)$ (figure 3).

\section{Clinical diagnosis}

Majority of the patients were diagnosed with haemoglobin E (HbE)/ $\beta$-thalassaemia $(2744 / 7984,34.37 \%)$, followed 


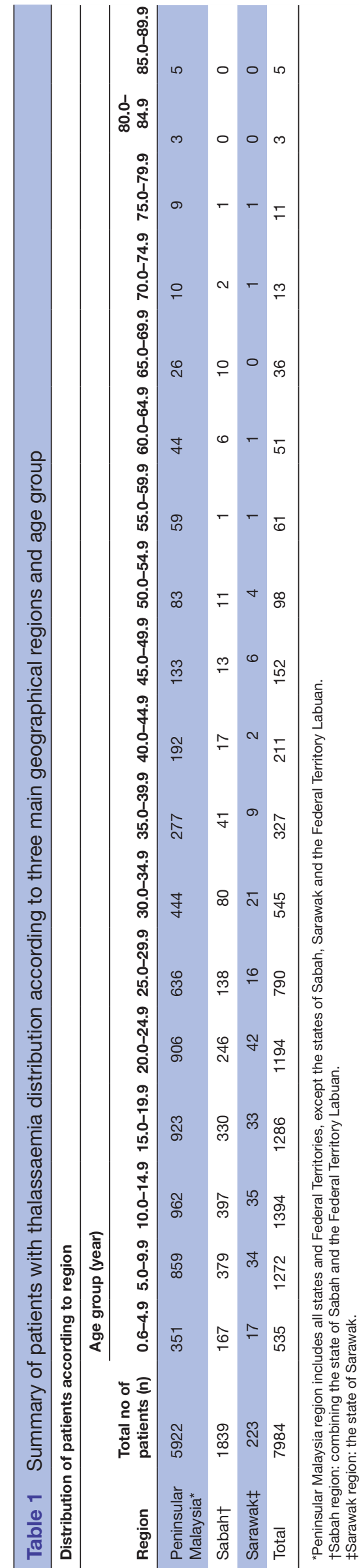

by $\beta$-thalassaemia major (TM) $(2676,33.52 \%)$, haemoglobin $\mathrm{H}(\mathrm{HbH})$ disease $(1458,18.26 \%), \beta$-thalassaemia intermedia $(748,9.37 \%)$ and 'others' $(358,4.48 \%)$. The 'others' group includes other forms of $\mathrm{HbH}$ disease, $\mathrm{Hb}$ Lepore Hollandia, $\alpha$-thalassaemia syndrome, $\delta \beta$-thalassaemia and other thalassaemia disorders requiring regular blood transfusions.

A pattern of clinical diagnosis can be observed in certain age groups and ethnicity. Of the total registered patients aged $<15.0$ years old (3201 patients), 1186 were diagnosed with TM $(37.05 \%)$. Patients aged $25.0-44.9$ years old were commonly reported with $\mathrm{HbE} / \beta$-thalassaemia $(707 / 1873,37.75 \%)$, while patients aged $\geq 55.0$ years old were commonly diagnosed with $\mathrm{HbH}$ disease $(86 / 180$, $47.78 \%)$. These observations were consistent with the presentation of the clinical diagnosis; TM presents early in life, the severity of $\mathrm{HbE} / \beta$-thalassaemia ranges from mild to severe, while $\mathrm{HbH}$ disease is non-transfusion dependent thalassaemia (non-TDT), and patients are most likely to survive longer due to the lower risk of iron overload. Figure 2 shows the peak of patient distribution corresponds to the age group of 10.0-14.9 years for TM, $15.0-19.9$ years for $\mathrm{HbE} / \beta$-thalassaemia, and $10.0-14.9$ years for $\mathrm{HbH}$ disease and $\beta$-thalassaemia intermedia, respectively.

In relation to ethnicity, patients with $\mathrm{HbE} / \beta$-thalassaemia were frequently reported among the Malay. Two thousand four hundred and forty-one out of 5106 (47.81\%) Malay patients were diagnosed with $\mathrm{HbE} / \beta$-thalassaemia and $2441 / 2744(88.96 \%)$ of the $\mathrm{HbE} / \beta$-thalassaemia were of Malay patients. TM was predominant in the KadazanDusuns $(783 / 907,86.33 \%)$. Another interesting note is a high proportion of Chinese patients were diagnosed with $\mathrm{HbH}$ disease $(297 / 938,31.66 \%)$ in comparison to the other ethnicities.

\section{Regular transfusion}

Four thousand five hundred and twenty-nine out of 7984 (56.73\%) patients require regular blood transfusions. Regular blood transfusions is defined as requiring red blood cell transfusions biweekly or up to once every 12 weeks. The remaining patients were classified as nonTDT which consists of patients who were on irregular blood transfusions (>16 weeks intervals) or who had never needed transfusion therapy.

\section{Chelation therapy}

There was 4928 of 7984 patients $(61.72 \%)$ on iron chelation therapy. The most common iron chelator monotherapy prescribed was deferasirox (DFX) $(1645 / 4928$ patients, $33.38 \%$ ), followed by deferiprone (DFP) (1107, $22.46 \%$ ) and desferrioxamine (DFO) (963, 19.54\%). Combination therapies were prescribed for the remaining patients: DFO and DFP (910, 18.47\%); DFO and DFX (169, 3.43\%); DFP and DFX (92, 1.87\%); and DFO, DFP and DFX (42, 0.85\%).

Oral iron chelator, DFX was commonly prescribed for the young patients aged $<15.0$ years old $(1231 / 1836$, 


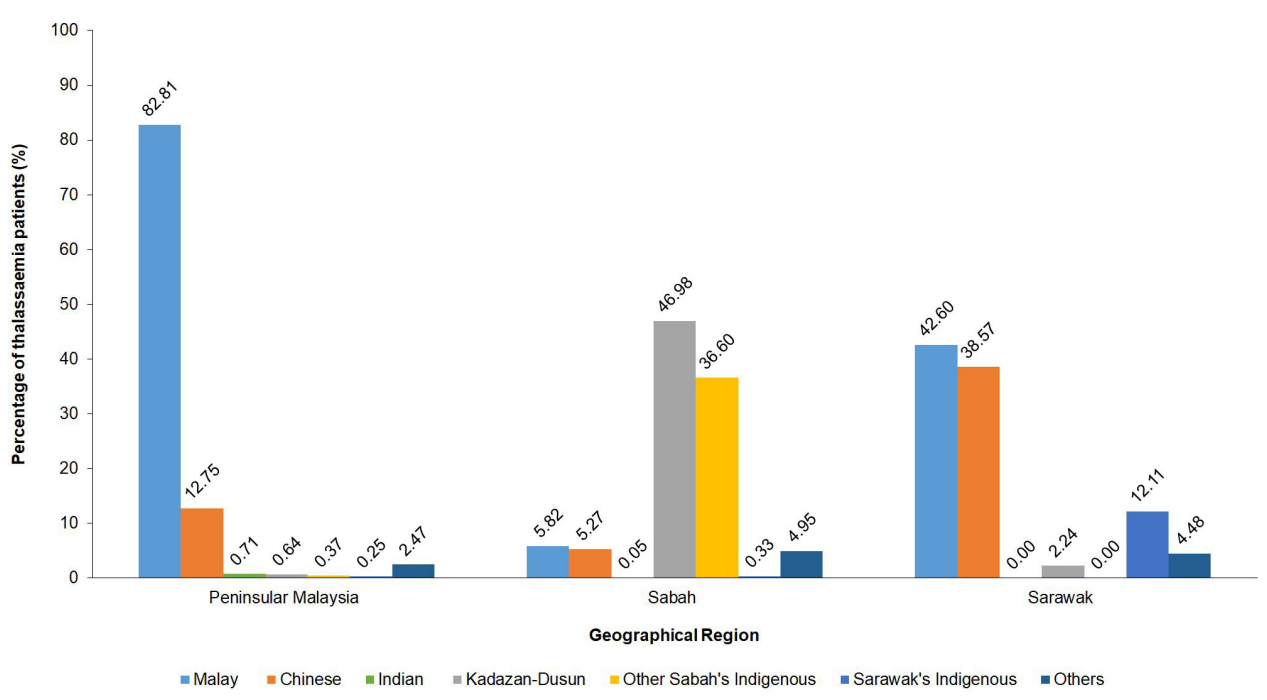

Figure 3 Percentage of patients with thalassaemia according to ethnicities and geographical region. The percentage was calculated against the total number of patients in each respective geographical region. 'Other Sabah's Indigenous' includes Pribumi Sabah, Bajau, Murut, Rungus and Sino Kadazan; 'Sarawak's Indigenous' includes Pribumi Sarawak, Iban, Bidayuh and Melanau; and 'others' includes Orang Asli, Thais, mixed ethnicities, foreigners and other ethnicities.

$67.05 \%)$. Meanwhile oral DFP was commonly prescribed for the adult patients aged $\geq 30.0$ years $(457 / 888,51.46 \%)$.

Overall, majority of the patients $(3715 / 4928,75.39 \%)$ were given single chelation therapy. There was a higher number of patients in the age group 20.0-24.9 years old $(330 / 4928,6.70 \%)$ who were prescribed combination therapy but patients above 25.0 years old were commonly prescribed single chelation therapy.

\section{History of splenectomy}

Splenectomy was performed in 1235 out of 8681 patients (14.23\%). This was performed mainly in the older aged patients, who were not on iron chelation therapy or had chronic iron overload. Almost $80 \%$ of the splenectomy were carried out in those with TM $(43.15 \%)$ and $\mathrm{HbE} / \beta$-thalassaemia $(41.78 \%)$, followed by thalassaemia intermedia $(7.61 \%)$ and $\mathrm{HbH}$ disease $(6.77 \%)$.

\section{Serum ferritin levels}

Data on ferritin levels were available for 3091 (38.71\%) of the registered cases. As there were many missing data on ferritin levels despite multiple or serial results entered for individual patients, the registry could only generate report on the most recent ferritin levels recorded for each patient. Overall, $562(18.18 \%)$ patients had ferritin levels $<1000 \mu \mathrm{g} / \mathrm{L} ; 1087(35.17 \%)$ patients had ferritin levels between 1000 and $2499 \mu \mathrm{g} / \mathrm{L} ; 820(26.53 \%)$ patients had ferritin levels between 2500 and $4999 \mu \mathrm{g} / \mathrm{L} ; 511$ (16.53\%) patients had ferritin levels between 5000 and $9999 \mu \mathrm{g} / \mathrm{L}$; and $111(3.59 \%)$ patients had ferritin levels $\geq 10000 \mu \mathrm{g} / \mathrm{L}$.

\section{Birth summary}

The updated data on affected births was retrieved on 22 April 2020 during the revision of the writing. This is to obtain the actual numbers of affected births from 2007 to 2018, due to the dynamic nature of the database and patients were only registered in the MTR after diagnosis was made instead of on the year of birth. The total number of affected births was 1483, 1098 and 214 during 2007-2011, 2012-2016 and 2017-2018, respectively (online supplementary table 1). Overall, we observed a declining trend of affected birth from year 2015 onwards and this could likely explain the decreasing trend of total new cases between year 2016 and 2018 (388, 277 and 102 new cases, respectively) given the clinical manifestation of TDT. The highest reported number of thalassaemia birth was in 2008 with 334 babies were born and Sabah had the highest number of affected births compared to other states. From 2014 to 2018 new thalassaemia birth declined steadily especially in Sabah and this could be associated with increased public awareness due to initiatives carried out by the government besides screening of secondary school children. The causes of affected birth were not delineated.

\section{Deceased patients}

There were $697(8.03 \%)$ recorded deaths out of 8681 patients, of which $89(12.77 \%)$ had incomplete data. Overall, $72.31 \%$ death occurred in TM and $16.64 \%$ death in patients with $\mathrm{HbE} / \beta$-thalassaemia. The main causes of death among the 608 patients with thalassaemia with verifiable data were cardiac failures $(254,41.78 \%)$ and infections $(232,38.16 \%)$. Other causes were motor vehicle accidents $(18,2.96 \%)$, liver diseases $(16,2.63 \%)$, malignancy $(15,2.47 \%)$, endocrine complications (13, $2.14 \%)$, multiple organs dysfunction $(7,1.15 \%)$, surgical complications $(7,1.15 \%)$, thrombosis $(6,0.99 \%)$, central nervous system events $(5,0.82 \%)$ and others $(35,5.76 \%)$.

One hundred and eighty-three of 252 deaths (72.62\%) from cardiac causes were patients aged between 15.0 years and 29.9 years-69 cases $(27.38 \%$ ) aged $15.0-19.9$ years, 73 cases $(28.97 \%)$ aged 20.0-24.9 years and 41 cases $(16.27 \%)$ aged $25.0-29.9$ years. The majority of death 
from cardiac failures were observed among patients with TM $(190 / 254,74.80 \%)$ between 20.0 and 24.9 years of age followed by the 15.0-19.9 years of age group. The $\mathrm{HbE} / \beta$-thalassaemia patients recorded 38 deaths out of $254(14.96 \%)$ and a similar age group to TM. The majority of deaths was associated with chronic iron overload. Among the 96 TM deaths with recorded ferritin level, $38(39.58 \%)$ of them had ferritin level of 5000$9999 \mu \mathrm{g} / \mathrm{L}$ and $43(44.79 \%)$ of them had ferritin level of $\geq 10000 \mu \mathrm{g} / \mathrm{L}$. For the $\mathrm{HbE} / \beta$-thalassaemia deaths, 28 patients had recorded ferritin levels and $8(28.57 \%)$ of the 28 deaths were associated with both ferritin levels of $5000-9999 \mu \mathrm{g} / \mathrm{L}$ and $\geq 10000 \mu \mathrm{g} / \mathrm{L}$, respectively. Overall, more than $50 \%$ of the cardiac deaths were associated with severe chronic iron overload.

For infection deaths, 229 patients had complete data; the mean age of death was 22.0 years old $(\mathrm{SD} \pm 12.06)$ and those in age group 15.0-19.9 years old contributed to the highest mortality numbers $(57 / 229,24.89 \%)$, followed by patients aged between 20.0 and 24.9 years old $(49 / 229,21.40 \%)$ and patients in age group 25.0-29.9 years old $(28 / 229,12.23 \%)$. Most of the death occurred among patients with TM $(155 / 229,67.69 \%)$ followed by the $\mathrm{HbE} / \beta$-thalassaemia $(50 / 229,21.83 \%)$. Again, the majority of death was associated with chronic iron overload. Among the $81 \mathrm{TM}$ deaths with recorded ferritin level, $25(30.86 \%)$ and $23(28.40 \%)$ of them had ferritin level of $5000-9999 \mu \mathrm{g} / \mathrm{L}$ and $\geq 10000 \mu \mathrm{g} / \mathrm{L}$, respectively. For the $\mathrm{HbE} / \beta$-thalassaemia deaths, 40 patients had recorded ferritin levels and $19(47.50 \%)$ of the 40 deaths were associated with ferritin levels of $5000-9999 \mu \mathrm{g} / \mathrm{L}$ and $9(22.50 \%)$ deaths had ferritin levels $\geq 10000 \mu \mathrm{g} / \mathrm{L}$. Overall, more than $50 \%$ of the infection deaths were associated with severe chronic iron overload. We were not able to capture the most common organisms responsible for the fatal outcome as this was not documented in the death certificate. All causes of death were obtained from the death certificates and for infection mortality it was often written as septicaemia/sepsis or pneumonia only.

Only one patient had history of splenectomy in the infection death group. Four patients died from complications related to stem cell transplantation. The case records for deaths with incomplete data were unavailable and may have been archived.

\section{DISCUSSION}

This study highlights the current trend of thalassaemia in Malaysia through the data obtained from MTR. The MTR congregates data on patients with thalassaemia seeking treatment at the participating government hospitals and university hospitals nationwide. Through the report, comprehensive data on patient population, geographical locations, age groups, ethnicity and clinical diagnosis can be obtained. Furthermore, information on blood transfusions and chelation therapy outcomes obtained from the MTR can be studied to evaluate the efficacy of treatment received. The interpretation of treatment outcome data can be used to help improve patient management.

Before and during the early development of MTR in year 2007, local researchers could only estimate the prevalence of thalassaemia and other figures related to the disorder based on small, single-centred population or previous reports. The previous reports were mainly focused on molecular characterisation of thalassaemia or evaluation of quality of life outcome according to state, centre or ethnicity and did not include the actual figure of reported cases in the respective region where the study was conducted. ${ }^{8}{ }^{9}$ Reports on estimated thalassaemia carrier rate in Malaysia only referred to old data ${ }^{10-12}$ and the previous works describing the thalassaemia scenario in Malaysia had utilised data from the $\mathrm{MOH}$ annual report. ${ }^{13}$

The current estimate of the population of Malaysia is 32.6 million with Bumiputera (including Malay and indigenous people of Sabah and Sarawak, such as KadazanDusun) comprising $69.1 \%$ of the entire population. This is followed by Chinese $(23.0 \%)$, Indian $(6.9 \%)$ and 'Others' $(1.0 \%) .{ }^{14}$ In this study, patients of Indian ethnicity are small in number as the Malaysian Indians' ancestors, who were mostly from South India, rarely presented with $\alpha$-thalassaemia or $\beta$-thalassaemia. ${ }^{115-17}$

Malay ethnicity has a higher prevalence of $\mathrm{HbE} / \beta$-thalassaemia. A point mutation at $\mathrm{CD} 26$, the $\beta$-globin gene mutation causing $\mathrm{HbE}$ disease, is commonly detected in Malaysian Malay patients during molecular characterisation. ${ }^{11} 18$ The highest proportion of patients with $\mathrm{HbE} / \beta$-thalassaemia in the current study were found in Selangor, Kuala Lumpur, Kelantan and Kedah. The plausible factors are due to centralisation of thalassaemia referral centre (in the case of hospitals in Selangor and Kuala Lumpur), being close to the capital or centre of migration (Selangor in relation to Kuala Lumpur as capital of Malaysia) and being the border states (Kedah and Kelantan which promotes interaction between the populations of Thailand and Peninsular Malaysia).

TM is more common in the Kadazan-Dusuns ethnicity in Sabah due to a higher prevalence of Filipino $\beta$-thalassaemia deletion in the ethnicity. ${ }^{15}{ }^{19}$ Comprising $24.5 \%$ out of the Bumiputera population, ${ }^{20}$ the registered cases in the MTR signifies that a large proportion of KadazanDusuns are affected by TM.

$\mathrm{HbH}$ disease, which is commonly caused by the deletion of three $\alpha$-globin genes $(-/-\alpha)$, is predominant in the Malaysian Chinese. ${ }^{16}{ }^{17}$ Although a single $\alpha$-globin gene deletion like the $-\alpha^{3.7}$ rightward single $\alpha$-globin gene deletion $\left(-\alpha^{3.7} / \alpha \alpha\right)$ are also present in the Malays and Indians, the Southeast Asian double $\alpha$-globin gene deletion $\left(-{ }^{\mathrm{SEA}} /\right.$ $\alpha \alpha)$ that is common in the Malaysian Chinese is responsible for the clinical manifestation of the disease. ${ }^{16}$

In all registered patients, serum ferritin levels have been traditionally used for monitoring iron overload. In general, we observed a remarkable improvement in the trend of ferritin levels during the 12 years. The percentage of patients with ferritin levels of $\leq 2499 \mu \mathrm{g} / \mathrm{L}$ has increased 


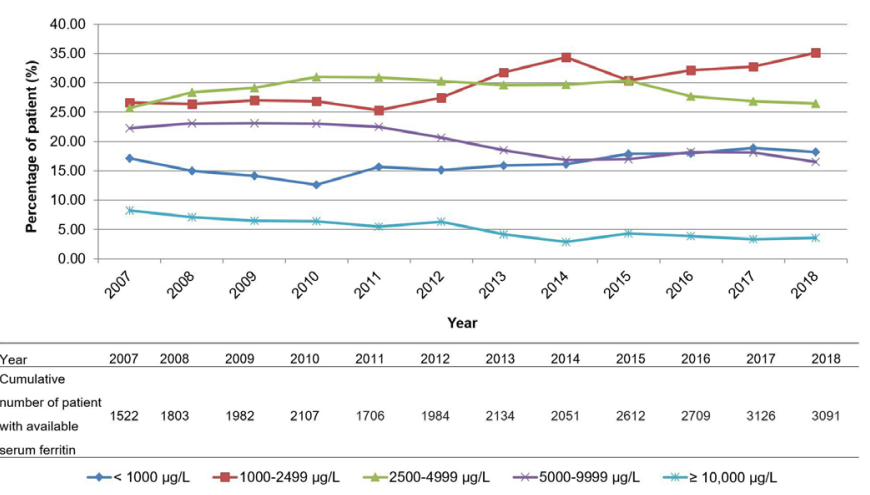

Figure 4 Serum ferritin levels of regularly transfused patients with thalassaemia between 2007 and 2018. The number of patients with ferritin level of $\leq 2499 \mu \mathrm{g} / \mathrm{L}$ have increased over time.

and was pronounced in the $1000-2499 \mu \mathrm{g} / \mathrm{L}$ group (from $406 / 1522(26.68 \%)$ in 2007 to $1087 / 3091(35.17 \%)$ in 2018) and the percentage of those with ferritin levels of $\geq 5000 \mu \mathrm{g} / \mathrm{L}$ has declined which was most remarkable in the $5000-9999 \mu \mathrm{g} / \mathrm{L}$ group $(339 / 1522(22.27 \%)$ in 2007 to $511 / 3091(16.53 \%)$ in 2018) (figure 4). The single measurement of ferritin levels reported here has limitation in overall interpretation of iron overload in the patients as the readings could be affected by inflammatory conditions. However, we believe that the overall report helps us to understand the status of management of iron overload in our patients over the years to enable planning for better monitoring.

In our report, $62 \%$ of TDT patients were on iron chelation therapy. Importantly, $61.7 \%$ of our patients had an iron overload of between 1000 and $4999 \mu \mathrm{g} / \mathrm{L}$. Approximately $3.6 \%$ of our patients had very high levels of ferritin of $\geq 10000 \mu \mathrm{g} / \mathrm{L}$ and about $16 \%$ of the patients had ferritin levels of 5000-9999 $\mathrm{g} / \mathrm{L}$, which underlines the need for optimisation of chelation therapy.

Early initiation of chelation therapy and close monitoring is paramount to prevent complications from iron overload. Here, clinicians are encouraged to prescribe iron chelator monotherapy whenever possible unless the chelation regime is inadequate to control the iron overload or patients are not compliant including intolerance towards subcutaneous infusion DFO of 8-12 hours. ${ }^{21}$ In such situations this could lead to a change from subcutaneous DFO to oral chelator DFX or DFP or a combination therapy. Oral chelator DFX, a dispersible tablet taken once daily is the preferred option observed in the current study as it is more feasible in younger patients as young as 2 years old compared to oral DFP, a tablet or capsule, taken three times daily. ${ }^{21}{ }^{22}$ In the analysis, the older patients were more likely have been started on DFP before the approval of DFX use in Malaysia in year $2005,{ }^{21}$ and then continue with the same medication. A combination therapy is usually initiated when intensive therapy is needed to overcome severe iron overload. Improvement in management of iron overload and improved compliance to iron chelators especially the oral preparations could likely explain for the declined levels of serum ferritin observed in the past few years. The oral DFX monotherapy was mainly prescribed to the young patients and oral DFP was given to the adult patients. Overall, the above findings of ferritin levels trend should be interpreted with caution as cardiac complications due to iron overload is still the leading cause of death among the patients with thalassaemia. Furthermore, the age groups with high mortality are rather young compared to other registry reports. ${ }^{23}$ Other complications like endocrine dysfunction were not specifically recorded in the MTR. However, hypogonadism was found to occur in $22 \%{ }^{24}$ of young adults and adults with TDT and short stature has also been reported. ${ }^{25}{ }^{26}$ Thus, intensification of chelation therapy, improvement on monitoring of iron overload and compliance to chelation therapy is needed in all patients.

In recent years, the government started investing in MRI T2* sequence, to evaluate and monitor myocardial iron concentration specifically. Radiologists were trained and the service can be accessed in a few regions in the country. Clinicians managing TDT are now able to access MRI T2* for active surveillance of iron overload and this will help them to optimise chelation therapy for their patients. ${ }^{2728}$ However, the MRI T2* data collection for the MTR has not started and the feasibility of entering the findings into the registry is under way.

Prevention of affected births is a challenge in Malaysia. To date, prenatal screening of thalassaemia is still very low although it can be conducted on request, and the cost is covered by the national health system if conducted in the government hospitals. Despite multiple meetings and forums with medical and religious experts, which have been conducted since 2004, a policy on prenatal screening and diagnosis is yet to be developed. The multiethnic cultures and religions practised in the country play a huge role in prenatal diagnosis and therapeutic abortion. In a local study, majority of the study respondents were open to prenatal diagnosis, but less than one-third agreed to performing both prenatal diagnosis followed by termination of affected fetuses. More than $75 \%$ of those declining claimed that religious restriction is the main reason. ${ }^{29}$ Accessibility to prenatal diagnosis in some regions and family planning consideration are also among the contributing factors.

In Malaysia, therapeutic abortion is permitted based on The Penal Code (Amendment) Act 1989 (Act A727), which allows abortion within 120 days of conception only if the continued pregnancy poses a greater threat to the mother's life or to her physical or mental health than would the termination of the pregnancy. Although this can affect the incidence of new TM cases, the current overall trend of affected births and newly diagnosed TDT cases suggests that the public awareness initiatives by $\mathrm{MOH}$ have given positive outcomes. Initiatives such as offering free early population screening, periodical health education and public awareness have helped to identify carriers and increased awareness on the risk of 
giving birth to a thalassaemic child. However, there were public concerns related to creating anxiety and stigmatising youth who are affected.

Overall, when we look at the trend of declining numbers of yearly new cases especially from 2015 onwards, we believe that continuous health education, public awareness programme and improved management of the thalassaemic in Malaysia over the last 10 years have provided positive return on the investment.

Although the MTR is able to identify and collect most of the important information on patients with thalassaemia nationwide, certain records are still incomplete. A limitation of the MTR report may pertain to the missing data in several variables of the total number of registered patients; serum ferritin levels, MRI T2* findings, end organs complication, causes of death and birth summary, as some details were not accessible or not recorded in the patients' notes. Furthermore, as the MTR is a dynamic, real-time web system, the numbers of reported cases change through time hence the figures might differ following periodical update of the report. For instance, the total number of affected births in year 2017 or 2018, may only be captured when the patients present with symptoms related to thalassaemia later than the year of birth. Therefore, a definite cut-off point is needed each time a report is generated to ensure the most updated data is presented.

\section{CONCLUSION}

The MTR has successfully demonstrated the time trends and most recent update of patients with thalassaemia in Malaysia over the past decade. We observed the disease landscape has changed significantly where many patients are now living past the second decade of life with improvement in patient management and quality of life. ${ }^{30}$ The continuously updated data entered into the MTR contributes to revealing the current disease status and to understand the progress of thalassaemia in Malaysia. Sustainability of the MTR is challenging as its maintenance requires ongoing support from the government, policy makers, research funding bodies and clinicians, however it provides a positive return on investment. It enables local health authorities and health providers to plan cost efficient services, improve treatment outcomes, enhance preventive strategies, reduce healthcare burden and ultimately improve the quality of life of patients with thalassaemia.

\footnotetext{
Author affiliations

${ }^{1}$ Division for Research and Technical Support, Ministry of Health Malaysia,

Putrajaya, Wilayah Persekutuan Putrajaya, Malaysia

${ }^{2}$ Department of Paediatrics, Hospital Tunku Azizah, Kuala Lumpur, Wilayah

Persekutuan Kuala Lumpur, Malaysia

${ }^{3}$ Department of Paediatrics, Sabah Women \& Children Hospital, Likas, Kota Kinabalu, Sabah, Malaysia

${ }^{4}$ Department of Paediatrics, Hospital Umum Sarawak, Kuching, Sarawak, Malaysia

${ }^{5}$ Department of Paediatrics, Hospital Pulau Pinang, Georgetown, Pulau Pinang,

Malaysia

${ }^{6}$ Department of Paediatrics, Hospital Raja Permaisuri Bainun, Ipoh, Perak, Malaysia
}

${ }^{7}$ Department of Paediatrics, Hospital Sultan Ismail, Johor Bharu, Johor, Malaysia ${ }^{8}$ Department of Paediatrics, Hospital Sultanah Nur Zahirah Kuala Terengganu, Kuala Terengganu, Terengganu, Malaysia

${ }^{9}$ Department of Paediatrics, UKM Medical Centre, The National University of Malaysia, Jalan Yaacob Latif, Cheras, Kuala Lumpur, Malaysia

${ }^{10}$ UKM Medical Molecular Biology Institute, Jalan Yaacob Latif, Cheras, Kuala Lumpur, Malaysia

${ }^{11}$ Department of Paediatrics, Hospital Universiti Sains Malaysia, Kota Bahru, Kelantan, Malaysia

${ }^{12}$ Department of Paediatrics, University of Malaya Medical Centre, Kuala Lumpur, Wilayah Persekutuan Kuala Lumpur, Malaysia

Acknowledgements The authors would like to thank the Ministry of Health, Malaysia for the approval to publish this article; the Malaysian Society of Paediatric Haematology and Oncology for the research grant managed by Clinical Research Malaysia Sdn Bhd for the development of this article; and MediConnexions Consulting Sdn Bhd for their writing assistance. The authors thank all central study coordinators and research assistants in each state, as follows: Mr Mohd Hafizudin Mohd Salim, Ms Faizah Mohd Hanapiah, Mr Mohamad Khudri Khairudin, Dr Ahmad Arif Hussin, Dr Muzaida Aminah Mohd, Ms Nur Asyilla Aslinda Mohd Nasir, Mr Muhammad Farid Abdul Ghaffar, Ms Siti Nur Syahida Abdul Jalil, Ms Nurul Shafika Mohd Hairi, Mr Mohd Saharudin Mat Salim, Ms Nurliyana Kamarolzaman, Ms Analisa Coldelia Anak Rumpu, Ms Elvyshirah Hadirin, Ms Raphaela Romanus, Ms Norafifa Mazlan, Mr Mohd Afiq Azis, Ms Hamizah Karber, Ms Nor Aimy Ramli, Ms Nur Zuliana Hashim, Ms Nur Athirah Abdul Razak, Mr Mohd Afiq Mohd Sulaiman and Ms Nurain Syahirah Abu Bakar.

Contributors HMI was the principal investigator. HMI, ZM, ISO, MNMU, KHT, AT, $\mathrm{KG}, \mathrm{GBO}$, SLY, AMR, CHCMR, NDD, ZAL, ARAJ, NM, HMA, and HA contributed to the design of the study, development of the work and data validation and provided intellectual input. HA revised, edited and made significant contributions to the final manuscript. All authors read and approved the final manuscript. MediConnexions Consulting Sdn Bhd provided writing assistance.

Funding The development of this article is supported by a research grant managed by The Malaysian Society of Paediatric Haematology and Oncology.

Map disclaimer The depiction of boundaries on this map does not imply the expression of any opinion whatsoever on the part of BMJ (or any member of its group) concerning the legal status of any country, territory, jurisdiction or area or of its authorities. This map is provided without any warranty of any kind, either express or implied.

\section{Competing interests None declared.}

Patient and public involvement Patients and/or the public were not involved in the design, or conduct, or reporting, or dissemination plans of this research.

Patient consent for publication Not required.

Ethics approval This study has been approved by Medical Research and Ethics Committee, Ministry of Health Malaysia (National Medical Research Register ID: NMRR-17-2410-37653).

Provenance and peer review Not commissioned; externally peer reviewed.

Data availability statement Data are available upon reasonable request. The data in this report were collected from the Malaysian Thalassaemia Registry. Any request to access the data must be made to the Ministry of Health, Malaysia.

Open access This is an open access article distributed in accordance with the Creative Commons Attribution Non Commercial (CC BY-NC 4.0) license, which permits others to distribute, remix, adapt, build upon this work non-commercially, and license their derivative works on different terms, provided the original work is properly cited, appropriate credit is given, any changes made indicated, and the use is non-commercial. See: http://creativecommons.org/licenses/by-nc/4.0/.

\section{ORCID iDs}

Hishamshah Mohd Ibrahim http://orcid.org/0000-0002-0689-3095

Hamidah Alias http://orcid.org/0000-0003-3952-5368

\section{REFERENCES}

1 Cao A, Kan YW. The prevention of thalassemia. Cold Spring Harb Perspect Med 2013;3:a011775.

2 Weatherall DJ. The evolving spectrum of the epidemiology of thalassemia. Hematol Oncol Clin North Am 2018;32:165-75. 
3 Ngim CF, Ibrahim H, Lai NM, et al. A single centre study on birth of children with transfusion-dependent thalassaemia in Malaysia and reasons for ineffective prevention. Prenat Diagn 2015;35:51-9.

4 Ismail A, Campbell MJ, Ibrahim HM, et al. Health related quality of life in Malaysian children with thalassaemia. Health Qual Life Outcomes 2006;4:39-46.

5 Kwiatkowski JL, Kim H-Y, Thompson AA, et al. Chelation use and iron burden in North American and British thalassemia patients: a report from the thalassemia longitudinal cohort. Blood 2012;119:2746-53.

6 Origa R. Beta-thalassemia. In: Adam MP, Ardinger HH, Pagon RA, eds. GeneReviews ${ }^{\circledR}$. Seattle, WA: University of Washington, 2018.

7 Noori T, Ghazisaeedi M, Aliabad GM, et al. International comparison of thalassemia registries: challenges and opportunities. Acta Inform Med 2019;27:58-63.

8 Fucharoen S, Fucharoen G, Ata K, et al. Molecular characterization and nonradioactive detection of beta-thalassemia in Malaysia. Acta Haematol 1990;84:82-8.

9 Thong MK, Soo TL. The spectrum of beta-globin gene mutations in children with beta-thalassaemia major from Kota Kinabalu, Sabah, Malaysia. Singapore Med J 2005;46:340-3.

10 Quek DL, Ng Y-Y, Wang W, et al. Rapid carrier screening for betathalassemia by single-step allele-specific PCR and detection. Clin Biochem 2007;40:427-30.

11 Tan JAMA, Chin PS, Wong YC, et al. Characterisation and confirmation of rare beta-thalassaemia mutations in the Malay, Chinese and Indian ethnic groups in Malaysia. Pathology 2006;38:437-41.

12 Thong M-K, Tan JAMA, Tan KL, et al. Characterisation of betaglobin gene mutations in Malaysian children: a strategy for the control of beta-thalassaemia in a developing country. J Trop Pediatr 2005;51:328-33.

13 Dahlui M, Hishamshah MI, Rahman AJA, et al. Quality of life in transfusion-dependent thalassaemia patients on desferrioxamine treatment. Singapore Med J 2009;50:794-9.

14 Department of Statistics Malaysia. Current population estimates, Malaysia, 2018-2019, 2019. Available: https://www.dosm.gov.my/v1/ index.php?r=column/pdfPrev\&id=aWJZRkJ4UEdKcUZpT2tVT090 Snpydz09

15 Tan J-AMA, Lee P-C, Wee Y-C, et al. High prevalence of alpha- and beta-thalassemia in the Kadazandusuns in East Malaysia: challenges in providing effective health care for an Indigenous group. $J$ Biomed Biotechnol 2010;2010:1-5.

16 Wee Y-C, Tan K-L, Chow TW-P, et al. Heterogeneity in alphathalassemia interactions in Malays, Chinese and Indians in Malaysia. J Obstet Gynaecol Res 2005;31:540-6.

17 Ahmad R, Saleem M, Aloysious NS, et al. Distribution of alpha thalassaemia gene variants in diverse ethnic populations in
Malaysia: data from the Institute for medical research. Int J Mol Sci 2013:14:18599-614.

18 Hanafi S, Hassan R, Bahar R, et al. Multiplex amplification refractory mutation system (MARMS) for the detection of $\beta$-globin gene mutations among the transfusion-dependent $\beta$-thalassemia malay patients in Kelantan, northeast of Peninsular Malaysia. Am J Blood Res 2014:4:33-40.

19 Teh LK, George E, Lai MI, et al. Molecular basis of transfusion dependent beta-thalassemia major patients in Sabah. J Hum Genet 2014:59:119-23.

20 Department of Statistics Malaysia. Population distribution and basic demographic characteristics. Putrajaya, Malaysia, 2010. https://www. dosm.gov.my/v1/index.php?r=column/ctheme\&menu_id=LOpheU43 NWJwRWVSZkIWdzQ4TIhUUT09\&bul_id=MDMxdHZjWTk1SjFzTzNk RXYzcVZjdz09

21 Shah NR. Advances in iron chelation therapy: transitioning to a new oral formulation. Drugs Context 2017;6:1-10.

22 Ministry of Health Malaysia. Management of transfusion dependent thalassaemia. Putrajaya, Malaysia: Medical Development Division, 2009. https://www.moh.gov.my/moh/attachments/8318.pdf

23 Voskaridou E, Kattamis A, Fragodimitri C, et al. National registry of hemoglobinopathies in Greece: updated demographics, current trends in affected births, and causes of mortality. Ann Hematol 2019;98:55-66.

24 Lee KT, Lim SL, Goh AS. Prevalence of endocrine complications in transfusion dependent thalassemia in hospital Pulau Pinang: a pilot study. Med J Malaysia 2020;75:33-7.

25 Hamidah A, Rahmah R, Azmi T, et al. Short stature and truncal shortening in transfusion dependent thalassemia patients: results from a thalassemia center in Malaysia. Southeast Asian J Trop Med Public Health 2001;32:625-30.

26 Tan KA, Lum SH, Yahya A, et al. Prevalence of growth and endocrine disorders in Malaysian children with transfusion-dependent thalassaemia. Singapore Med J 2019;60:303-8.

27 Karimi M, Amirmoezi F, Haghpanah S, et al. Correlation of serum ferritin levels with hepatic MRI T2 and liver iron concentration in nontransfusion beta-thalassemia intermediate patients: a contemporary issue. Pediatr Hematol Oncol 2017;34:292-7.

28 Jain S, Mehta N, Thora S. A study of serum ferritin, alanine transaminase and hepatic MRI T2 values in beta-thalassemia majo patients. Int J Contemp Pediatrics 2016;3:1367-70.

29 Ngim CF, Lai NM, Ibrahim $\mathrm{H}$, et al. Attitudes towards prenatal diagnosis and abortion in a multi-ethnic country: a survey among parents of children with thalassaemia major in Malaysia. $J$ Community Genet 2013;4:215-21.

30 Shafie AA, Chhabra IK, Wong JHY, et al. Health-Related quality of life among children with transfusion-dependent thalassemia: a crosssectional study in Malaysia. Health Qual Life Outcomes 2020;18:141. 